\title{
Article
}

Subscriber access provided by UNIVERSITY OF THE SUNSHINE COAST

\section{Hydrolysis of ammonia-borane over Ni/ZIF-8 nanocatalyst: high efficiency, mechanism and controlled hydrogen release}

Changlong Wang, Jimena Tuninetti, Zhao WANG, Chen Zhang, Roberto

Ciganda, Lionel Salmon, Sergio Moya, Jaime Ruiz, and Didier Astruc

J. Am. Chem. Soc., Just Accepted Manuscript • Publication Date (Web): 01 Aug 2017

Downloaded from http://pubs.acs.org on August 1, 2017

\section{Just Accepted}

"Just Accepted" manuscripts have been peer-reviewed and accepted for publication. They are posted online prior to technical editing, formatting for publication and author proofing. The American Chemical Society provides "Just Accepted" as a free service to the research community to expedite the dissemination of scientific material as soon as possible after acceptance. "Just Accepted" manuscripts appear in full in PDF format accompanied by an HTML abstract. "Just Accepted" manuscripts have been fully peer reviewed, but should not be considered the official version of record. They are accessible to all readers and citable by the Digital Object Identifier (DOI®). "Just Accepted" is an optional service offered to authors. Therefore, the "Just Accepted" Web site may not include all articles that will be published in the journal. After a manuscript is technically edited and formatted, it will be removed from the "Just Accepted" Web site and published as an ASAP article. Note that technical editing may introduce minor changes to the manuscript text and/or graphics which could affect content, and all legal disclaimers and ethical guidelines that apply to the journal pertain. ACS cannot be held responsible for errors or consequences arising from the use of information contained in these "Just Accepted" manuscripts. 


\title{
Hydrolysis of ammonia-borane over Ni/ZIF-8 nanocatalyst: high efficiency, mechanism and controlled hydrogen release
}

Changlong Wang, ${ }^{\S, \|}$ Jimena Tuninetti, ${ }^{\#}$ Zhao Wang, ' Chen Zhang, ${ }^{\S}$ Roberto Ciganda, Lionel Salmon, ${ }^{\S}$ Sergio Moya, ${ }^{\#}$ Jaime Ruiz, "Didier Astruc ${ }^{\prime \prime}$ *

${ }^{\S}$ Laboratoire de Chimie de Coordination, UPR CNRS 8241, 31077 Toulouse Cedex, France

"ISM, UMR CNRS N 5255, Univ. Bordeaux, 33405 Talence Cedex, France

\# CIC biomaGUNE, Unidad Biosuperficies, Paseo Miramon No 182, Edif “C”, 20009 Donostia-San Sebastian, Spain

Sorbonne Universités, UPMC Univ Paris 06, UMR CNRS 7197, Laboratoire de Réactivité de Surface, 4 Place Jussieu, Tour 43-33, 3ème étage, Case 178, F-75252 Paris, France

\begin{abstract}
Non-noble metal nanoparticles are notoriously difficult to prepare and stabilize with appropriate dispersion, which in turn severely limits their catalytic functions. Here using zeolitic imidazolate framework (ZIF-8) as MOF template, catalytically remarkably efficient ligand-free first-row late transition-metal nanoparticles are prepared and compared. Upon scrutiny of the catalytic principles in the hydrolysis of


ammonia-borane, the highest total turnover frequency among these first-row late transition metals is achieved for the templated $\mathrm{Ni}$ nanoparticles with 85.7 $\mathrm{mol}_{\mathrm{H} 2} \cdot \mathrm{mol}_{\mathrm{cat}}^{-1} \cdot \mathrm{min}^{-1}$ at room temperature, which overtakes performances of previous non-noble metal nanoparticles systems, and is even better than some noble metal nanoparticles systems. Mechanistic studies especially using kinetic isotope effects show that cleavage by oxidative addition of an $\mathrm{O}-\mathrm{H}$ bond in $\mathrm{H}_{2} \mathrm{O}$ is the rate determining steps in this reaction. Inspired by these mechanistic studies, an attractive and effective "on-off" control of hydrogen production is further proposed.

\section{Introduction}

Catalytic hydrogen generation from hydrogen storage materials is considered as a convenient, inexpensive, and effective approach to address the energy and environmental concern. ${ }^{1-4}$ Among various chemical hydrogen storage materials, ammonia-borane $(\mathrm{AB})$ has a high hydrogen content (19.6 wt\%), high stability in the solid state and solution under ambient conditions, nontoxicity, and high solubility. Therefore it is considered as one of the most leading contender in promising chemical hydrogen-storage materials for various applications. ${ }^{5-15}$

Until now, effective catalysts for hydrolysis of $\mathrm{AB}$ are typically based on expensive and rare noble metal nanocatalysts (e.g., Rh, Pt, Ru). Considerable efforts have been devoted to the design of high-performance noble metal-free nanocatalysts, ${ }^{16-25}$ On the other hand, the hydrolysis of $\mathrm{AB}$ under mild conditions by cheap and earth-abundant 
first row metal nanoparticles ( $\mathrm{Fe}, \mathrm{Co}, \mathrm{Ni}$ and $\mathrm{Cu}$, "BM") with practical efficiency and sustainability remains extremely challenging, largely due to their labile nature, complex mechanistic manifolds and low catalytic efficiencies. ${ }^{26}$

Supported nanoparticle (NP) catalysts have shown remarkable catalytic efficiencies. It has also been found, however, that the activities were significantly influenced or/and eventually determined by the NP supports. ${ }^{27-37}$ In this regard, metal organic frameworks (MOFs) are outstanding emerging porous nanomaterials that are advantageous compared to other conventional inorganic supports. ${ }^{38-43}$ MOFs allow confining and stabilizing catalytically active metal NPs within their frameworks, which controls the nucleation and growth of NPs, thus preventing their aggregation and prolonging their stabilities. ${ }^{44-51}$ Moreover, the high specific surface areas and tunable pore sizes ensured good NP dispersion, which allows exposing active sites and facilitates the accessibility of substrates to the active NP surface by reducing diffusion resistance. ${ }^{44-51}$ On the other hand, the direct use of nanoconfinement effect by MOFs provides a facile method to prepare ligand-free and ultrafine NP/MOF nanocatalysts, which is significant but also crucial for the design of highly efficient heterogeneous catalysts. However, the comparison of the catalytic efficiencies of BMNPs using the same MOF template have not yet been disclosed.

In addition to the rational design of new nanocatalysts, insights to the mechanistic aspects of the hydrolysis reaction would be essential for the enhancement of the catalytic efficiencies of the BMNPs/MOFs nanocatalysts. The details of the reaction process of $\mathrm{AB}$ hydrolysis over $\mathrm{BMNPs} / \mathrm{MOF}$ nanocatalysts again have rarely been 
experimentally examined, however. In order to address these challenging issues, we now report the synthesis, characterization and catalytic functions of the BMNPs/zeolitic imidazolate framework (ZIF-8; $\left.\left[\mathrm{Zn}(\mathrm{MeIM})_{2}\right]_{\mathrm{n}}\right)$ nanocatalysts, especially with efforts to further improve the catalytic activity by understanding the mechanistic aspects of the hydrolysis reaction. First, the supporting nanomaterial of ZIF-8 is synthesized and characterized. Then we highlight the efficiency of Ni NPs/ZIF-8 nanocatalyst by comparing the catalytic activities of first-row late transition-metals NPs/ZIF-8 catalysts in the hydrolysis of $\mathrm{AB}$ in water under mild conditions. Subsequently we scrutinize the catalytic behavior of Ni NPs/ZIF-8 nanocatalysts for the hydrolysis of $\mathrm{AB}$ in water, the mechanistic aspects of this reaction using kinetic isotope effects (KIEs), and an anion effect for the control of hydrogen release. The catalytic activity of the nanocatalyst Ni NPs/ZIF-8 surpassed all the non-noble metal NP systems for the hydrolysis of AB.

\section{Result and discussion}

Synthesis and characterizations of the nanocatalysts: The ZIF- 8 nanoparticles ${ }^{52}$ are first rapidly synthesized in water using a modified method (SI). ${ }^{53}$ Transmission electron microscope (TEM) image indicates that the ZIF-8 NPs are nanocrystals with sharp hexagonal facets, and the average size of ZIF-8 NPs is around $75 \mathrm{~nm}$ (Figure S1). Powder X-ray diffraction (PXRD) proves the pure phase of ZIF-8 nanomaterial (Figure S2). ZIF-8 NPs show a type I isotherm in the $\mathrm{N}_{2}$ adsorption measurement. The 
presence of micropores results in volume increase adsorbed at very low relative pressures, whereas a second uptake at a high relative pressure indicates the existence of textural meso/macroporosity formed by the packing of NPs (Figure S3). The Brunauer-Emmett-Teller (BET) surface area of ZIF-8 NPs is $1663.3 \mathrm{~m}^{2} \mathrm{~g}^{-1}$. Refluxing the ZIF-8 NPs in either methanol or water during one day does not change the framework structure, as evidenced from the unchanged PXRD patterns (Figure S2), showing the thermal and chemical stabilities of ZIF-8 NPs. ${ }^{52,53}$

The nanocatalysts BMNPs/ZIF-8 are prepared using the deposition-precipitation (DP) method with fast reduction by $\mathrm{NaBH}_{4}$, then collected by centrifugation followed by washing and drying in vacuo (Scheme 1 and SI). These nanomaterials are clearly distinguished by their colors (compare the photographs in Figure S4); for instance Ni NPs/ZIF-8 appears grey, whereas $\mathrm{Cu}$ NPs/ZIF-8 is completely black. No diffractions are detected for Ni NP species from PXRD patterns after reduction in Ni NPs/ZIF-8 compared to ZIF-8 NPs, which indicates that Ni loadings are too low or Ni NPs are too small. ${ }^{49,54}$ The metal loading is determined by inductively coupled plasma-optical emission spectroscopy (ICP-AES); for instance the Ni loading in Ni NPs/ZIF-8 is 2.2 $\mathrm{wt} \%$. The metal oxidation state is then identified by X-Ray photoelectron spectroscopy (XPS). Binding energies (B.E.) of 1021.4 and $1044.5 \mathrm{eV}$ are observed for the $2 p_{3 / 2}$ and $2 p_{1 / 2}$ levels of the $\mathrm{Zn}^{2+}$ ion in the ZIF- 8 framework, respectively (Figure S5). Moreover the well-defined peaks with B.E. of 852.2 and $870.1 \mathrm{eV}$ are detected for the $2 \mathrm{p}_{3 / 2}$ and $2 \mathrm{p}_{1 / 2}$ levels (Figure $\mathrm{S} 6$ ), respectively, of metallic $\mathrm{Ni}^{0}$ in the Ni NPs. ${ }^{17,21}$ 


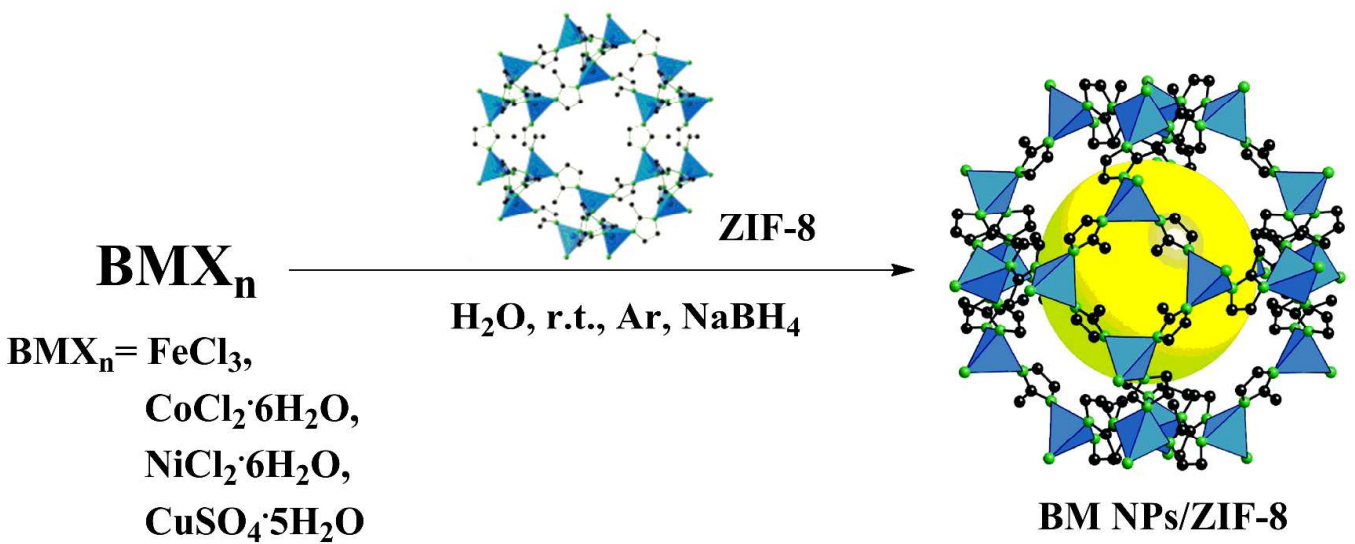

Scheme 1. Preparations of the nanocatalysts BMNP/ZIF-8.

Interestingly, after the deposition of the BMNPs, the nanocatalysts BMNPs/ZIF-8 become more spherical, as exemplified by NiNPs/ZIF-8 (Figures 1a and 1b). The measurements of the NP size by TEM encounters problems, however, probably due to their small sizes and lack of contrast over ZIF-8 framework. In order to release the BMNPs from the nanocatalysts BMNPs/ZIF-8 for direct TEM characterization, the ZIF-8 framework was then digested using a solution of ethylenediaminetetraacetic acid $(\mathrm{EDTA})^{55}$ in the presence of poly(vinylpyrrolidone) $(\mathrm{PVP}, \mathrm{Mw}=10,000)$ to stabilize the ultrasmall NPs. In this way the sizes of the BMNPs are successfully measured by TEM (Table 1). The size of the released NiNPs is $2.7 \mathrm{~nm}$, and other size distributions of FeNPs, CoNPs, and CuNPs are shown in Table 1 and in the SI (Figures S7-S10). On the other hand, nitrogen sorption experiments of the nanocatalysts show type I shape and considerable decrease of pore volume and BET surface areas (Table 1 and Figure S3). This indicates blocking of the windows of the ZIF-8 framework cavities by highly dispersed NPs within the locally distorted 
environment or/and the location of NPs at the surface; the latter was also shown by TEM in Figure 1b, for instance for NiNPs/ZIF-8.

Table 1. Physical properties and catalytic efficiencies of the nanocatalysts.

\begin{tabular}{|c|l|l|l|l|}
\hline Sample & \multicolumn{1}{|c|}{ Size $^{\mathrm{a}}$} & \multicolumn{1}{|c|}{ BET surface } & Pore volume & \multicolumn{1}{|c|}{$\mathrm{TOF}^{\mathrm{b}}$} \\
& $(\mathrm{nm})$ & \multicolumn{1}{c|}{$\left(\mathrm{cm}^{3} \mathrm{~g}^{-1}\right)$} & $\left(\mathrm{mol}_{\mathrm{H} 2} \cdot \mathrm{mol}_{\mathrm{cat}}{ }^{-1} \cdot \mathrm{min}^{-1}\right)$ & \\
\hline ZIF-8 & $75 \pm 3$ & 1663.3 & 0.6614 & -- \\
\hline FeNPs/ZIF-8 & $3.0 \pm 0.4$ & 1313.3 & 0.4491 & 2.5 \\
\hline CoNPs/ZIF-8 & $2.9 \pm 0.3$ & 1313.8 & 0.4539 & 19.4 \\
\hline NiNPs/ZIF-8 & $2.7 \pm 0.3$ & 1324.3 & 0.4255 & $35.3 / 85.7^{\mathrm{c}}$ \\
\hline CuNPs/ZIF-8 & $3.2 \pm 0.4$ & 1367.3 & 0.4110 & 5.6 \\
\hline
\end{tabular}

${ }^{a}$ TEM size. ${ }^{b}$ Hydrolysis of $\mathrm{AB}$ in water at room temperature $\left(25 \pm 0.5^{\circ} \mathrm{C}\right), \mathrm{TOF}=$ $\mathrm{mol}_{H 2}$ released $/\left(\mathrm{mol}_{\text {catalyst }} \times\right.$ reaction time $\left.(\min )\right) .{ }^{c}$ TOF is obtained in the presence of $0.3 \mathrm{M} \mathrm{NaOH}$. 


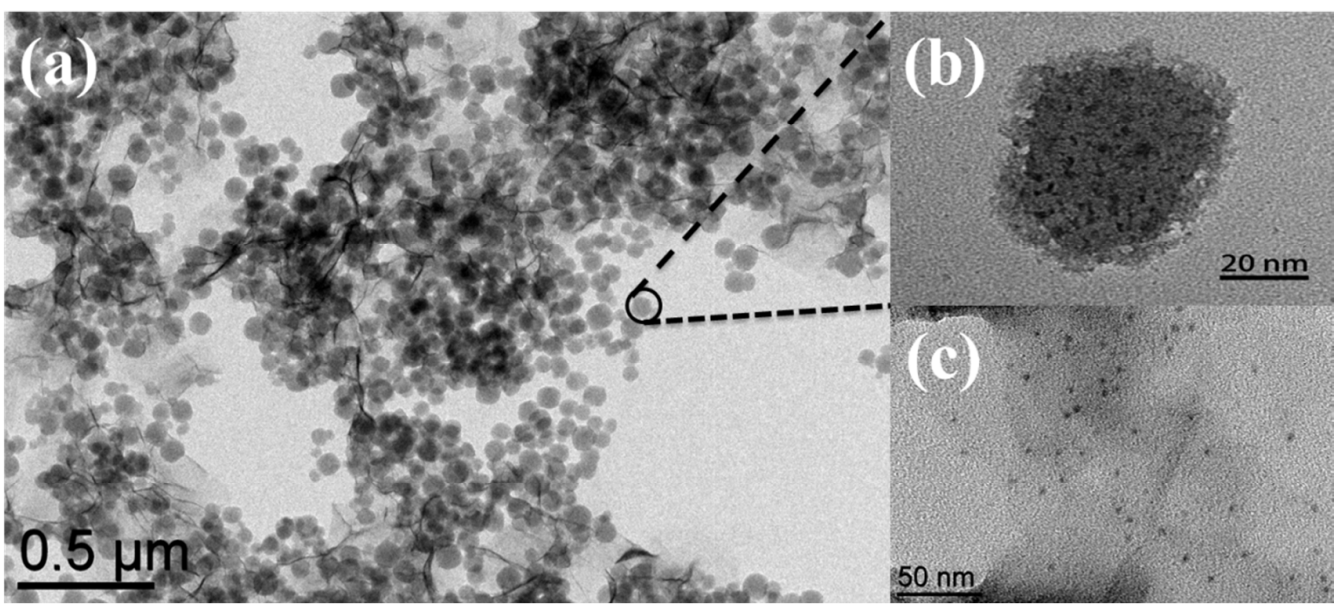

Figure 1. TEM images of NiNPs/ZIF-8: (a) at $500 \mathrm{~nm}$ scale. (b) at $20 \mathrm{~nm}$ scale. (c) NiNPs in NiNPs/ZIF-8 after digestion using EDTA and capping with PVP.

High efficiency of NiNPs/ZIF-8 in the hydrolysis of AB and mechanistic studies.

The catalytic performances of the BMNPs/ZIF-8 are evaluated for the hydrolysis of $\mathrm{AB}$ reaction in water. Hydrolysis of $\mathrm{AB}$ starts in water by employing $3 \mathrm{~mol} \%$ of the various late transition metal nanocatalysts BMNPs/ZIF-8 (measured by ICP-AES). The reaction profile in the presence of the nanocatalysts BMNPs/ZIF-8 is shown in Figure S11. The volumes of gas collected represent nearly 3 equiv. $\mathrm{H}_{2}$ per $\mathrm{AB}$ with no detectable $\mathrm{NH}_{3}(\mathrm{SI}),{ }^{56}$ indicating that hydrolysis of $\mathrm{AB}$ catalyzed by the nanocatalyst BMNPs/ZIF-8 proceeds according to Equation (1):

$$
\mathrm{H}_{3} \mathrm{NBH}_{3}+2 \mathrm{H}_{2} \mathrm{O} \underset{\text { r.t., } \mathrm{H}_{2} \mathrm{O}}{\stackrel{\text { BMNPs/ZIF-8 nanocatalysts }}{\longrightarrow}} \mathrm{NH}_{4}^{+}+\mathrm{BO}_{2}^{-}+3 \mathrm{H}_{2}
$$

This comparison demonstrates the best activity of NiNPs/ZIF-8 in terms of turn over 
frequency (TOF) among the four nanocatalysts BMNPs/ZIF-8 (Table 1 and Figure S11). Therefore the catalytic system NiNPs/ZIF-8 was chosen for further studies.

Figure S12 shows the logarithmic plot of the hydrogen generation rate vs. concentration of NiNPs/ZIF-8; the slope is 0.98 , indicating that the hydrolysis of $\mathrm{AB}$ catalyzed by NiNPs/ZIF-8 is first-order with respect to the catalyst concentration. On the other hand hydrolysis of AB catalyzed by NiNPs/ZIF-8 is zero-order with respect to the $\mathrm{AB}$ concentration, as a nearly horizontal line (slope of 0.086) is observed (Figure S13). This implies that under the present reaction conditions, AB is easily activated, and thus the possibility of the activation of $\mathrm{AB}$ in the rate-determining step (RDS) is ruled out. This also is in accordance with the KIE results (vide infra). The activation energy $\left(E_{a}\right)$ of $\mathrm{AB}$ hydrolysis, determined by measuring the time dependence of $\mathrm{H}_{2}$ generation at various temperatures, is approximately $42.7 \mathrm{~kJ} / \mathrm{mol}$ (Figure S14 and calculation). This value also is lower than those found for several known noble metal-based nanocatalysts (Table S1).

Although the catalytic rates in the hydrolysis of $\mathrm{AB}$ catalyzed by NiNPs/ZIF-8 is independent of the $\mathrm{AB}$ concentration, the $\mathrm{KIE}^{57-59}$ was further investigated in order to shed light on the RDS of hydrolysis of AB catalyzed by NiNPs/ZIF-8. Indeed in this reaction the KIE value should tell if $\mathrm{N}-\mathrm{H}$ or $\mathrm{B}-\mathrm{H}$ or both bonds are broken during the RDS. $^{16,60-63}$

The hydrolysis of the deuterated products of $\mathrm{AB}$ (for their synthesis, see S.I.) in the presence of NiNPs/ZIF-8 shows slower reaction rates (Figure S17). A KIE of 1.33 is determined for deuteration at the boron site $\left(\mathrm{NH}_{3} \mathrm{BD}_{3}\right)$, indicating a similar 
dehydrogenation behavior to that of $\mathrm{AB}$ in $\mathrm{H}_{2} \mathrm{O}$. This indicates that the absence of large KIE for hydrolysis of $\mathrm{AB}$ deuterated at the boron site $\left(\mathrm{NH}_{3} \mathrm{BD}_{3}\right)$. On the other hand, the KIE value of 2.49 is calculated according to the $\mathrm{H}_{2}$ generation rates in $\mathrm{ND}_{3} \mathrm{BH}_{3}\left(\mathrm{NH}_{3} \mathrm{BH}_{3}-\mathrm{D}_{2} \mathrm{O}\right.$ system), suggesting that the $\mathrm{O}-\mathrm{H}$ bond cleavage of $\mathrm{H}_{2} \mathrm{O}$ might be in the RDS. This would be similar to the metal-catalyzed borohydride hydrolysis, in which half of the hydrogen comes from water. ${ }^{64}$ Previously, it has been suggested that the water activation by means of oxidative addition of a $\mathrm{O}-\mathrm{H}$ bond on noble metal NP surfaces easily occurs, forming adsorbed $-\mathrm{OH}$ and $-\mathrm{H}$ species. For instance Pt NPs have been known as the redox catalyst for water photo-splitting. ${ }^{65,66}$ That $\mathrm{Ni}$ is the best metal found here for the hydrolysis reaction among those four first-row late transition metals is in accord with oxidative addition of water as the RDS, because $\mathrm{Ni}(0)$ is known by far the best first-row metal catalyst of reactions involving oxidative addition. ${ }^{67}$ In addition the involvement of water activation in the RDS may be partially explained by the higher O-H bond energy $\left(\sim 493 \mathrm{~kJ} \mathrm{~mol}^{-1}\right)^{68}$ than that of $\mathrm{B}-\mathrm{N}$ and $\mathrm{B}-\mathrm{H}$ bond $\left(\sim 117\right.$ and $\sim 430 \mathrm{~kJ} \mathrm{~mol}^{-1}$, respectively $){ }^{69}$ Thus it is mostly likely that the water molecule is activated by an indirect $\mathrm{O}-\mathrm{H}$ bond cleavage to form $-\mathrm{H}$ and $-\mathrm{OH}$ species promoted by $\mathrm{AB}$ in the presence of the nanocatalyst NiNPs/ZIF-8. Since the $\mathrm{NH}_{3}$ group does not participate in the hydrolysis, the B-N bond dissociates in $\mathrm{AB}$, followed by $\mathrm{H}_{2}$ release (Figure 2). 


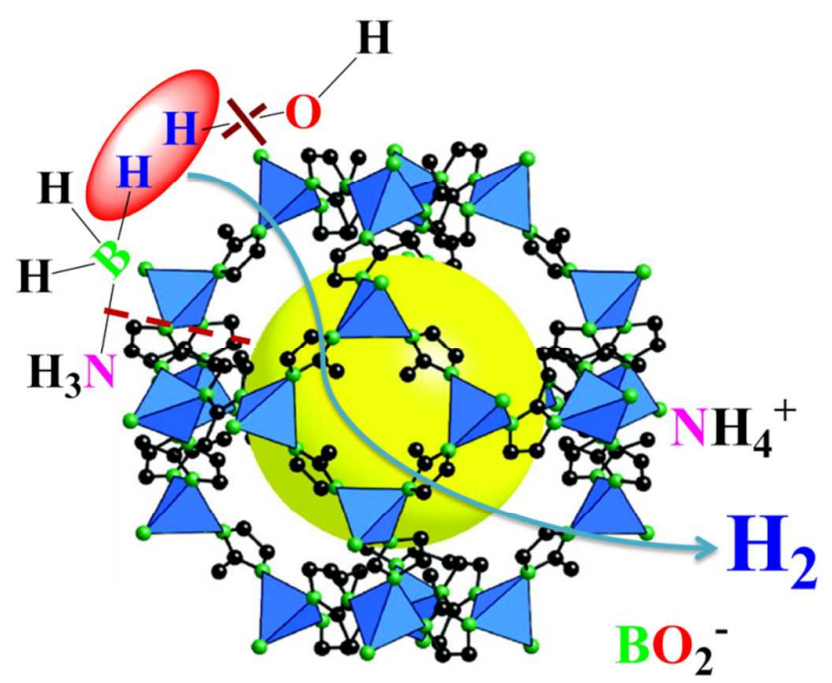

Figure 2. Proposed mechanism for the hydrolysis of AB catalyzed by NiNPs/ZIF-8.

\section{Remarkable improvement of the catalytic performance by ion effect allowing the}

controlled release of hydrogen. From the mechanistic studies, it can be assumed that if $\mathrm{OH}^{-}$is directly adsorbed on the surface of the $\mathrm{Ni}$ nanocatalyst, a bifunctional catalyst with both $\mathrm{H}$ and $\mathrm{OH}$ adsorptions should be highly expected to provoke the surface reaction. Thus the presence of surface $\mathrm{OH}^{-}$should be of great value for the enhancement of the catalytic activity. To verify this hypothesis, various concentrations of $\mathrm{NaOH}$ (0.1-0.4 M), a conventional $\mathrm{OH}^{-}$provider in aqueous solution, were separately added to the reaction media that only contained NiNPs/ZIF-8. After stirring for $30 \mathrm{~min}$, the aqueous solution of $\mathrm{AB}$ was added, and the catalytic activities were examined. Surprisingly, as shown in Figure $\mathrm{S} 18$, the $\mathrm{H}_{2}$ generation rates greatly improved as compared to the one in the absence of $\mathrm{NaOH}$. The $\mathrm{H}_{2}$ generation rates first increased with the increased $\mathrm{NaOH}$ concentrations $(0.1-0.3 \mathrm{M})$, then decreased with higher $\mathrm{NaOH}$ concentration $(0.4 \mathrm{M})$. It is suggested that the accumulation of too 
much $\mathrm{OH}^{-}$beyond the optimum level $(0.3 \mathrm{M})$ could significantly reduce the beneficial effect, resulting in the decrease of the $\mathrm{H}_{2}$ generation rate. The highest reaction rate in term of TOF is $85.7 \mathrm{~mol}_{\mathrm{H} 2} \cdot \mathrm{mol}_{\text {cat }-1} \cdot \min ^{-1}$ with $0.3 \mathrm{M} \mathrm{NaOH}$, showing the best activity among all the non-noble metal NP systems. This is even more efficient than noble metal NPs systems (Table S1); for instance the utilization of commercial 40 wt \% $\mathrm{Pt} / \mathrm{C}$ catalyst only had a TOF of $55.56 \mathrm{~mol}_{\mathrm{H} 2} \cdot \mathrm{molcat}^{-1} \cdot \mathrm{min}^{-1}$. Control experiment shows that the addition of $\mathrm{NaOH}$ has no effect on $\mathrm{AB}$ in aqueous solution in the absence of catalyst, as no $\mathrm{H}_{2}$ release is observed, as also confirmed by the ${ }^{1} \mathrm{H}$ and ${ }^{11} \mathrm{~B}$ NMR spectra. ${ }^{70}$ On the other hand, other bases such as $\mathrm{Na}_{2} \mathrm{CO}_{3}$ and $\mathrm{NaHCO}_{3}$ have no influence or slow down the $\mathrm{H}_{2}$ generation rate (SI).

In parallel the hydrolysis reaction was also conducted under identical conditions, except that $\mathrm{NaOH}$ was replaced by $\mathrm{HCl}(0.3 \mathrm{M}$ solution for the final concentration), and it was surprisingly found that there was no hydrogen release. Thus in the present study, the contribution from $\mathrm{OH}^{-}$predominated. The influence of $\mathrm{OH}^{-}$and $\mathrm{H}^{+}$ disclosed here is different from the very recent work involving $\mathrm{AB}$ hydrolysis by single $\mathrm{Rh}$ atoms $/ \mathrm{VO}_{2}$ nanorods, which showed positive correlation between the $\mathrm{H}^{+}$ concentration and the reaction rate. $^{71}$

Density functional theory (DFT) calculations on the interaction of $\mathrm{H}$ and $\mathrm{OH}$ with (111) metal Ni surface suggested that $\mathrm{H}$ forms an essentially covalent bond with the metal, whereas $\mathrm{OH}$ forms a largely ionic bond. ${ }^{72}$ The weaker covalent interaction and a stronger Pauli repulsion of the $\mathrm{OH}$ with the metal $d$ electrons result in the preference of binding molecular hydroxyl to Ni surface rather than $\mathrm{H}^{73,74}$ Moreover, Ni is more 
oxophilic than $\mathrm{Pt}$, so that it can better promote surface $\mathrm{OH}$ adsorption than $\mathrm{Pt} .{ }^{75}$ To confirm this, XPS is re-called to measure the surface binding energy of Ni $2 p$ upon treatment with $\mathrm{NaOH}$. As shown in Figure $\mathrm{S} 23$, upon treatment with $\mathrm{NaOH}$, the binding energy at $855.6 \mathrm{eV}$ that associates with $\mathrm{Ni}(\mathrm{OH})_{2}$ species $^{76}$ becomes predominant, verifying the coordination of $\mathrm{OH}$ group to the Ni surface. On the other hand, a $c a$. $0.76 \mathrm{eV}$ Ni $2 \mathrm{p}$ binding energy downshift was also observed. Thus upon coordination of $\mathrm{OH}$ group to the Ni surface, the $\mathrm{OH}$ adsorbates donate electrons to the Ni surface. This results in an increased electron density around the Ni surface, which facilitates the interaction with the reactant, $\mathrm{AB}$. The $E_{a}$ of $\mathrm{AB}$ hydrolysis in the presence $0.3 \mathrm{M} \mathrm{NaOH}$ was considerably decreased to $28.0 \mathrm{~kJ} / \mathrm{mol}$ (Figure S24). Therefore the overall reaction activity is significantly improved.

The reason for the switch off of hydrogen generation possibly comes from two aspects. One of them is the negative effect of $\mathrm{H}^{+}$on the self-ionization of water that suppresses the $\mathrm{OH}^{-}$formation and occupation of $\mathrm{OH}^{-}$absorption sites on the NiNP surface. The other one is the ion effect, because $\mathrm{Cl}^{-}$ligands are known to limit the catalytic activity of NPs by strongly bonding to NPs surface, which inhibits access to the surface active sites. We thus first conducted the initial reaction by adding $\mathrm{NaCl}$ solution $(0.3 \mathrm{M})$, and found that the $\mathrm{H}_{2}$ generation rate was slower than that without $\mathrm{NaCl}$ solution. $\mathrm{H}_{2}$ was released smoothly, however, with a TOF of 16.67 $\mathrm{mol}_{\mathrm{H} 2} \cdot \mathrm{mol}_{\mathrm{cat}}{ }^{-1} \cdot \min ^{-1}$ (Figure S25). This result suggests the possible ion effect in the reaction. To confirm this ion effect, other aqueous solutions of for instance NaI, $\mathrm{NaBF}_{4}, \mathrm{NaBr}, \mathrm{NaF}$, and $\mathrm{Na}_{2} \mathrm{SO}_{4}$ were then added to the reaction media with final 
concentration of $0.3 \mathrm{M}(\mathrm{SI})$. The $\mathrm{H}_{2}$ generation rates were considerably slowed down compared with the initial reaction preformed with only NiNPs/ZIF-8, and the TOFs were $10.3,13.7,16.2,18.5$ and $21.4 \mathrm{~mol}_{\mathrm{H} 2} \cdot \mathrm{mol}_{\mathrm{cat}}{ }^{-1} \cdot \mathrm{min}^{-1}$ for $\mathrm{NaI}, \mathrm{NaBF}_{4}, \mathrm{NaBr}, \mathrm{NaF}$ and $\mathrm{Na}_{2} \mathrm{SO}_{4}$, respectively. Interestingly, the catalytic activities follow the order: $\mathrm{SO}_{4}{ }^{2-}>$ $\mathrm{F}^{-}>\mathrm{Cl}^{-}>\mathrm{Br}^{-}>\mathrm{I}^{-}$, which also follows the direct Hofmeister series. Significant ion effects occurred and showed correlations with the catalytic activities obtained in the hydrolysis of $\mathrm{AB}$ reaction, a characteristic fingerprint of the Hofmeister effects. It is suggested that $\mathrm{H}^{+}$plays a very negative effect in the hydrolysis reaction. On the other hand, ions such as $\mathrm{Cl}^{-}, \mathrm{F}^{-}, \mathrm{Br}^{-}$et al present in the solution prefer to bind to the surface active sites of NiNPs, leaving less active surface sites available to $\mathrm{OH}^{-}$generated from water activation in the RDS of hydrolysis. Thus the negative synergistic effects switched off the hydrogen release. Therefore here we establish for the first time that the anion effect tuned hydrolysis of AB catalyzed by the nanocatalyst NiNPs/ZIF-8 in water, allowing the hydrogen generation to reversibly turn "off" and "on". This property is of great practical importance for on-board hydrogen applications under ambient conditions (vide infra).

The "on-off" control of hydrogen generation is achieved by addition of an equimolar amount of aqueous solution of $\mathrm{HCl}$ and $\mathrm{NaOH}$ to the reaction media (Figure 3). Through the studies above, $\mathrm{OH}^{-}$facilitates the hydrolysis reaction, while $\mathrm{H}^{+}$and $\mathrm{Cl}^{-}$ play negative roles in the hydrolysis of $\mathrm{AB}$. At the beginning of the hydrolysis reaction, $\mathrm{H}_{2}$ generation can be completely stopped by adding $0.3 \mathrm{M} \mathrm{HCl}$ solution, and the $\mathrm{H}_{2}$ generation is released again by adding the same $\mathrm{NaOH}$ molarity. In this way, 
the $\mathrm{H}_{2}$ generation is controlled. In addition, in each “on-off” cycle, a gradual decrease in the $\mathrm{H}_{2}$ generation is also observed. Indeed the poisoning effect of $\mathrm{H}^{+}$dominates the switch off of the $\mathrm{H}_{2}$ generation. The subsequent addition of $\mathrm{NaOH}$ neutralizes the $\mathrm{HCl}$ solution, however. The effect of $\mathrm{NaCl}$ production (from $\mathrm{NaOH}+\mathrm{HCl}$ ) was also observed in the medium, also considerably slowing down the $\mathrm{H}_{2}$ generation (vide supra).

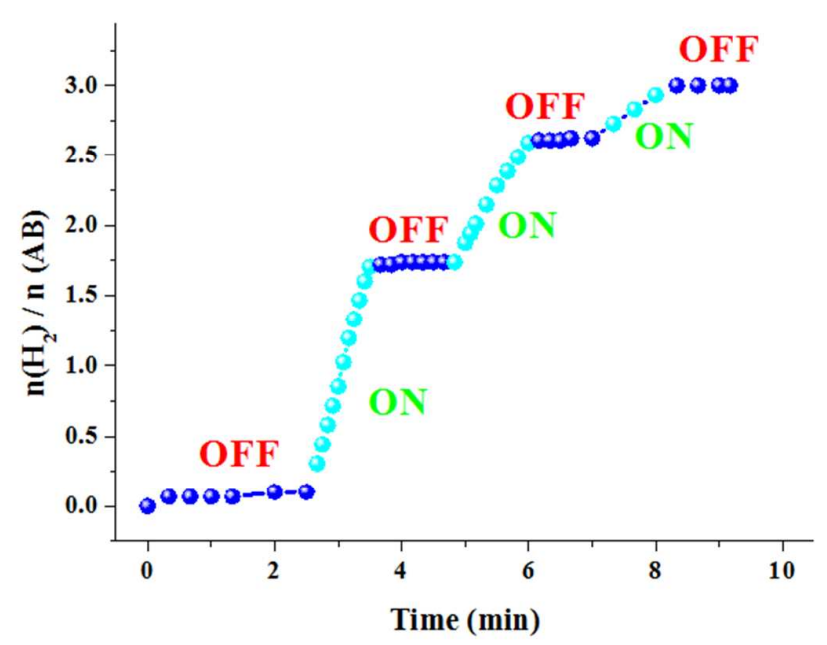

Figure 3. "On-off" control of $\mathrm{H}_{2}$ production in the $\mathrm{AB}$ hydrolysis in water.

Finally, we examined the reusability of the nanocatalyst NiNPs/ZIF-8, which is a critical issue for further practical applications. The reusability tests were conducted under the present conditions by continuous addition of a new proportion of $\mathrm{AB}$ aqueous solution when the previous run was completed. As shown in Figure 4, the activity of NiNPs/ZIF-8 is essentially retained until the fifth runs, where a slight drop 
in reaction rate is observed. The nanocatalyst was then characterized after the fifth runs by PXRD and TEM techniques, PXRD showing the unchanged nanostructure (Figure S30), while TEM showed the increase of NiNP size (Figure S31). Thus the decrease in the activity is ascribed to the diluted reactant in water, the deactivation effect of the hydrolysis product metaborate, ${ }^{77-79}$ and to the increased NiNP size, especially for NPs at the surface of ZIF-8.

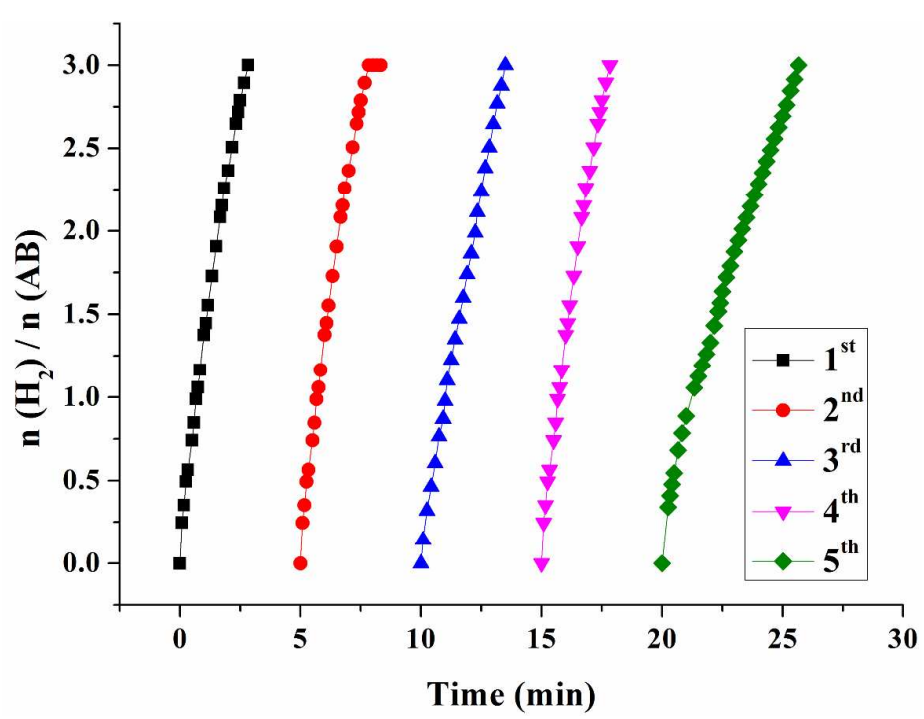

Figure 4. Plots of volume of $\mathrm{H}_{2}$ vs. time for the hydrolysis of $\mathrm{AB}$ catalyzed by the $3 \%$ NiNPs/ZIF-8 during the reusability test.

Concluding remarks. In summary, highly dispersed ligand-free Fe NPs, Co NPs, Ni NPs and $\mathrm{Cu}$ NPs have been successfully synthesized using ZIF-8 as nanocatalyst template, and the highest catalytic activity for hydrogen generation upon hydrolysis of $\mathrm{AB}$ is shown to be that of NiNPs/ZIF-8 showing a TOF value of 85.7 $\mathrm{mol}_{\mathrm{H} 2} \cdot \mathrm{mol}_{\mathrm{cat}}{ }^{-1} \cdot \mathrm{min}^{-1}$. This represents the best TOF value ever reported for noble 
metal-free catalysts. Detailed mechanistic investigations, especially KIE measurements, show that the RDS for $\mathrm{AB}$ hydrolysis is the cleavage of an $\mathrm{O}-\mathrm{H}$ bond in $\mathrm{H}_{2} \mathrm{O}$ by means of oxidative addition of such a bond on Ni NP surfaces. Inspired by this approach, we further disclosed the ion effect in this reaction, which allowed a remarkable improvement of the catalytic performance and the controlled release of hydrogen. The principles and results obtained here may not only provide insights into the rational design of highly efficient non-noble metal-based nanocatalysts, but also demonstrate a promising step towards the application of chemical hydrogen storage materials in a fuel-cell-based hydrogen economy.

\section{ASSOCIATED CONTENT}

Supporting Information. Syntheses and characterization of the nanocatalysts. ${ }^{1} \mathrm{H}$ NMR spectra of the products. Profiles of hydrolysis of the AB hydrolysis reactions. This material is available free of charge via the Internet at http://pubs.acs.org.

\section{AUTHOR INFORMATION}

\section{Corresponding Author}

*Author to whom correspondence should be addressed.

E-mail: didier.astruc@,u-bordeaux.fr

Notes

The authors declare no competing financial interest.

17 


\section{ACKNOWLEDGMENT}

Record of an XPS spectrum of Ni-ZIF-8 nanomaterial from and helpful discussion with Luis Yate (CIC biomaGUNE) and financial support from the China Scholarship Council (CSC) of the People's Republic of China (grant to C.W.), the Universities of Toulouse 3 and Bordeaux, the Centre National de la Recherche Scientifique (CNRS), and CIC biomaGUNE (FP7-PEOPLE-IRSES- HIGRAPHEN Project ID: 612704) are gratefully acknowledged.

\section{REFERENCES}

1 Armaroli, N.; Balzani, V. ChemSusChem 2011, 4, 21-36.

2 Yang, J.; Sudik, A.; Wolverton, C.; Siegel, D. J. Chem. Soc. Rev. 2010, 39, 656675.

3 Li, Z.; Xu, Q. Acc. Chem. Res. 2017, 50, 449-1458.

4 He, T.; Pachfule, P.; Wu, H.; Xu, Q.; Chen, P. Nat. Rev. Mater. 2016, 1, 16059.

5 Chandra, M.; Xu Q. J. Power Sources 2006, 156, 190-194.

6 Hamilton, C. W.; Baker, R. T.; Staubitz, A.; Manners, I. Chem. Soc. Rev. 2009, 38, $279-293$.

7 Staubitz, A.; Robertson, A. P. M.; Manners, I. Chem. Rev. 2010, 110, 4079-4124.

8 Zhu, Q. L.; Xu, Q. Energy Environ. Sci. 2015, 8, 478-512.

18 
9 Rossin, A.; Peruzzini, M. Chem. Rev. 2016, 116, 8848-8872.

10 Zhu, Q. -L.; Xu, Q. Chem 2016, 1, 220-245.

11 Zhan, W. -W.; Zhu, Q. -L.; Xu, Q. ACS Catal. 2016, 6, 6892-6905.

12 Akbayrak, S.; Özkar S. In Hydrogen Production Technologies, pp. 207-230, Sankir, M. and Sankir, N. D.; ed.; Wiley-VCH: Weinheim, Germany, 2017.

13 Yang, Q. H.; Xu, Q.; Yu, S. H.; Jiang, H. L. Angew.Chem., Int .Ed. 2016, 55, 3685-3689.

14 Khalily, M. A.; Eren, H.; Akbayrak, S.; Susapto, H. H.; Biyikli, N.; Özkar, S.; Guler, M. O. Angew. Chem. Int. Ed. 2016, 55, 12257 -12261.

15 J. -X. Kang, T. -W. Chen, D. -F. Zhang, L. Guo, Nano Energy 2016, 23, 145-152.

16 Li, Z.; He, T.; Liu, L.; Chen, W.; Zhang, M.; Wu, G.; Chen, P. Chem. Sci. 2017, 8, 781-788.

17 Mahyari, M.; Shaabani, A. J. Mater. Chem. A, 2014, 2, 16652-16659.

18 Yu, C.; Fu, J.; Muzzio, M.; Shen, T.; Su, D.; Zhu, J.; Sun, S. Chem. Mater., 2017, 29, 1413-1418.

19 Zhou, L.; Meng, J.; Li, P.; Tao, Z.; Mai, L.; Chen, J. Mater. Horiz., 2017, 4, $268-273$

20 Bulut, A.; Yurderi, M.; Ertas, I. E.; Celebi, M.; Kaya, M.; Zahmakiran, M. Appl. Catal. B: En. 2016, 180, 121-129.

21 Yin, H.; Kuwahara, Y.; Mori, K.; Cheng, H.; Wen, M.; Yamashita, H. J. Mater. Chem. A 2017, 5, 8946-8953.

22 Liu, P.; Gu, X.; Kang, K.; Zhang, H.; Cheng, J.; Su, H. ACS Appl. Mater.

19 
Interfaces 2017, 9, 10759-10767.

23 Zhang, H.; Gu, X.; Liu, P.; Song, J.; Cheng, J.; Su, H. J. Mater. Chem. A 2017, 5, 2288-2296.

24 Tang, C.; Xie, L.; Wang, K.; Du, G.; Asiri, A. M.; Luo, Y.; Sun, X. J. Mater. Chem. A 2016, 4, 12407-12410.

25 Feng, K.; Zhong, J.; Zhao, B.; Zhang, H.; Xu, L.; Sun, X.; Lee, S. -T. Angew. Chem., Int. Ed. 2016, 55, 11950-11954.

26 Wang, D.; Astruc, D. Chem. Soc. Rev. 2017, 46, 816-854.

27 Yang, Q.; Xu, Q.; Jiang, H.-L. Chem. Soc. Rev. 2017, DOI: 10.1039/C6CS00724D.

28 Astruc, D.; Lu, F.; Ruiz, J. Angew. Chem., Int. Ed. 2005, 44, 7852-7872.

29 Navalon, S.; Dhakshinamoorthy, A.; Alvaro, M.; Garcia, H. Coord. Chem. Rev. 2016, 312, 99-148.

30 Fihri, A.; Bouhrara, M.; Nekoueihahraki, B.; Basset, J. M.; Polhettiwar, V. Chem. Soc. Rev. 2011, 40, 5181-5203.

31 Gross, E.; Liu, J. H. -C.; Toste, F. D.; Somorjai, G. A. Nat. Chem. 2012, 4, 947-952.

32 Bai, C.; Liu, M. Nano Today 2012, 7, 258-281.

33 Scholden, J. D.; Leal, B. C.; Dupont, J. ACS Catal. 2012, 2, 184-200.

34 Sankar, M.; Dimitratos, N.; Miedjack, P. J.; Wells, P. P.; Kiely, C. J.; Hutchings, G. J. Chem. Soc. Rev. 2012, 41, 8099-8139.

35 Haruta, M. Angew. Chem. Int. Ed. 2014, 53, 52-56.

36 Amiens, C.; Ciuculescu-Pradines, D.; Philippot, K. Coord. Chem. Rev. 2016, 308, 
409-432.

37 Xia, Y.; Gilroy, K. D.; Peng, H.-C.; Xia, X. Angew. Chem., Int. Ed. 2017, 56, $60-95$.

38 Lee, J.Y.; Farha, O. K.; Roberts, J.; Scheidt, K. A.; Nguyen, S. T.; Hupp, J. T. Chem. Soc. Rev. 2009, 38, 1450-1459.

39 Farrusseng, D.; Aguado, S.; Pinel, C. Angew. Chem., Int. Ed. 2009, 48, 7502-7513.

40 Zeng, L.; Guo, X.; He, C.; Duan, C. ACS Catal. 2016, 6, 7935-7947.

41 Liu, J.; Chen, L.; Cui, H.; Zhang, J.; Zhang, L.; Su, C. -Y. Chem. Soc. Rev. 2014, 43, 6011-6061.

42 Chughtai, A. H.; Ahmad, N.; Younus, H. A.; Laypkov, A.; Verpoort, F. Chem. Soc. Rev. $\mathbf{2 0 1 5}, 44,6804-6849$.

43 Dhakshinamoorthy, A.; Garcia, H. Chem. Soc. Rev. 2012, 41, 5262-5284.

44 Lu, G.; Li, S.; Guo, Z.; Farha, O. K.; Hauser, B. G.; Qi, X.; Wang, Y.; Wang, X.; Han, S.;

Liu, X.; DuChene, J. S.; Zhang, H.; Zhang, Q.; Chen, X.; Ma, J.; Loo, S. C. J.; Wei, W. D.; Yang, Y.; Hupp, J. T.; Huo, F. Nat. Chem. 2012, 4, 310-316.

45 Choi, K. M.; Na, K.; Somorjai, G. A.; Yaghi, O. M. J. Am. Chem. Soc. 2015, 137, 7810-7816.

46 Na, K.; Choi, M.; Yaghi, O. M.; Somorjai, G. A. Nano Lett. 2014, 14, 5979-5983.

47 Rungtaweevoranit, B.; Baek, J.; Araujo, J. R.; Archanjo, B. S.; Choi, K. M.; Yaghi, O. M.; Somorjai, G. A. Nano Lett. 2016, 16, 7645-7649.

48 Aijaz, A.; Karkamkar, A.; Choi, Y. J.; Tsumori, N.; Rönnebro, E.; Autrey, T.; Shioyama, H.; Xu, Q. J. Am. Chem. Soc. 2012, 134, 13926-13929. 
49 Zhao, M.; Yuan, K.; Wang, Y.; Li, G.; Guo, J.; Gu, L.; Hu, W.; Zhao, H.; Tang, Z. Nature 2016, 539, 76-80.

50 An, B.; Zhang, J.; Cheng, K.; Ji, P.; Wang, C.; Lin, W. J. Am. Chem. Soc. 2017, 139, $3834-3840$.

51 Choi, K. M.; Kim, D.; Rungtaweevoranit, B.; Trickett, C. A.; Barmanbek, J. T. D.; Alshammari, A. S.; Yang, P.; Yaghi, O. M. J. Am. Chem. Soc. 2017, 139, 356-362. 52 Park, K. S.; Ni, Z.; Cote, A. P.; Choi, J. Y.; Huang, R.; Uribe-Romo, F. J.; Chae, H. K.; O’Keeffe, M.; Yaghi, O. M. Proc. Natl. Acad. Sci. U.S.A. 2006, 103, 1018610191.

53 Pan, Y.; Liu, Y.; Zeng, G.; Zhao, L.; Lai, Z. Chem. Commun. 2011, 47, 2071-2073.

54 Yurderi, M.; Bulut, A.; Zahmakiran, M.; Gülcan, M.; Özkar, S. Appl. Catal. B: Environ. 2014, 160, 534-541.

55 Lu, G.; Hupp, J. T. J. Am. Chem. Soc. 2010, 132, 7832-7833.

56 Metin, Ö.; Mazumder, V.; Özkar, S.; Sun, S. J. Am. Chem. Soc. 2010, 132, 1468-1469.

57 Westaway, K. C. J. Labelled Compd. Radiopharm. 2007, 50, 989-1005.

58 Guella, G.; Patton, B.; Miotello, A. J. Phys. Chem. C 2007, 111, 18744-18750.

59 Simmons, E. M.; Hartwig, J. F. Angew. Chem., Int. Ed. 2012, 51, 3066-3072.

60 Keaton, R. J.; Blacquiere, J. M.; Baker, R. T. J. Am. Chem. Soc. 2007, 129, $1844-$ 1845 .

61 Bhattacharya, P.; Krause, J. A.; Guan, H. J. Am. Chem. Soc. 2014, 136, $11153-11161$. 
62 Buss, J. A.; Edouard, G. A.; Cheng, C.; Shi, J.; Agapie, T. J. Am. Chem. Soc. 2014, $136,11272-11275$.

63 Chen, W.; Li, D.; Wang, Z.; Qian, G.; Sui, Z.; Duan, X.; Zhou, X.; Yeboah, I.; Chen, D. AIChE J. 2017, 63, 60-65.

64 Liu, B. H.; Li, Z. P. J. Power Sources 2009, 187, 527-534.

65 Lehn, J. -M.; Sauvage, J. -P. Nouv. J. Chim. 1977, 1, 449-451.

66 Hagfeldt, A.; Grätzel, M. Chem. Rev. 1995, 95, 49-68.

67 Astruc, D. Organometallic chemistry and catalysis; Springer: Berlin, New York, 2007.

68 Rablen, P. R. J. Am. Chem. Soc. 1997, 119, 8350-8360.

69 Peebles, L. R.; Marshall, P. J. Chem. Phys. 2002, 117, 3132-3138.

70 Fu, Z.-C.; Xu, Y.; Chan, S. L.-F.; Wang, W.-W.; Li, F.; Liang, F.; Chen, Y.; Lin, Z.-S.;

Fu, W.-F.; Che, C.-M. Chem. Commun. 2017, 53, 705-708.

71 Wang, L.; Li, H.; Zhang, W.; Zhao, X.; Qiu, J.; Li, A.; Zheng, X.; Hu, Z.; Si, R.; Zeng, J. Angew. Chem., Int. Ed. 2017, 56, 4712-4718.

72 Koper, M. T. M.; van Santen, R. A. J. Electroanal. Chem. 1999, 472,126-136.

73 Gómez, E. del V.; Amaya-Roncancio, S.; Avalle, L. B.; Linares, D. H.; Gimenez, M. C. Appl. Sur. Sci. 2017, 420, 1-8.

74 Bengaard, H. S.; Nørskov, J. K.; Sehested, J.; Clausen, B. S.; Nielsen, L. P.; Molenbroek, A. M.; Rostrup-Nielsen, J. R. J. Catal. 2002, 209, 365-384.

75 Wang, C.; Chi, M.; Wang, G.; van der Vliet, D.; Li, D.; More, K.; Wang, H.-H.; Schlueter, J. A.; Markovic, N. M.; Stamenkovic, V. R. Adv. Funct. Mater. 2011, 21, 
$147-152$.

76 Grosvenor, A. P.; Biesinger, M. C.; St.C. Smart, R.; McIntyre, N. S. Surf. Sci. 2006, $600,1771-1779$.

77 Zhu, Q. -L.; Li, J.; Xu. Q. J. Am. Chem. Soc. 2013, 135, 10210-10213.

78 Rakap, M. Appl. Catal. B: En. 2015, 163, 129-134.

79 Chen, W.; Ji, J.; Feng, X.; Duan, X.; Qian, G.; Li, P.; Zhou, X.; Chen, D.; Yuan, W.

J. Am. Chem. Soc. 2014, 136, 16736-16739.

TOC

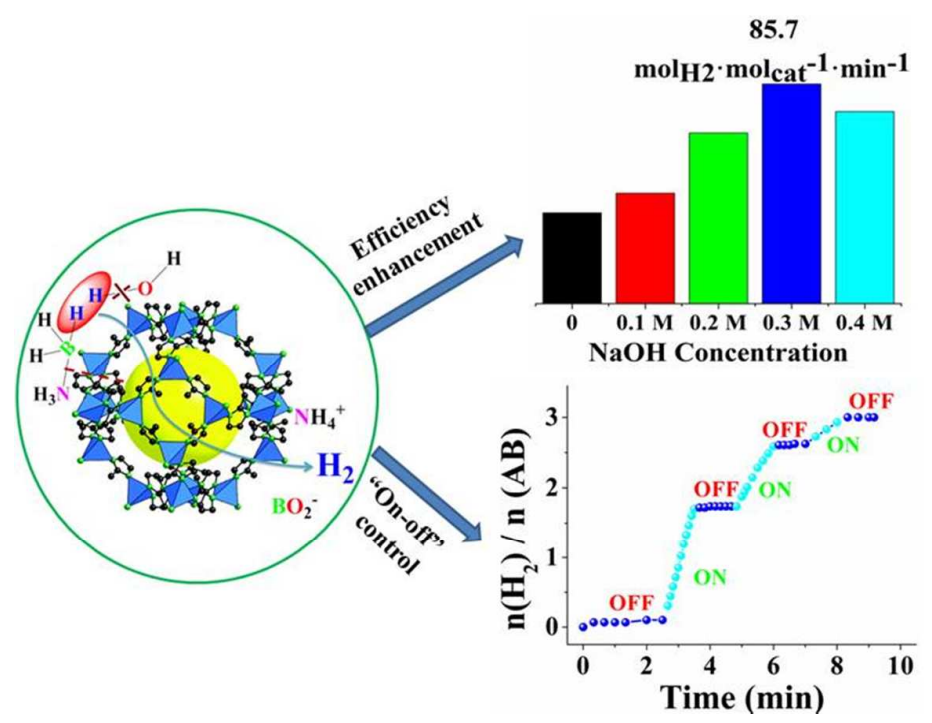

24 